\title{
EVOLUTION OF THE SCIENTIFIC AND METHODOLOGICAL APPROACHES TO THE ANALYSIS AND ASSESSMENT OF REGIONAL SOCIO-ECONOMIC DIFFERENTIATION ${ }^{1}$
}

\author{
Mikhail Y. Kazakov \\ Belgorod National Research University, Belgorod, Russian Federation \\ Inna V. Mitrofanova \\ Federal Research Centre The Southern Scientific Centre of the Russian Academy of Sciences, \\ Rostov-on-Don, Russian Federation
}

\begin{abstract}
Formation of a holistic and effective methodology of the system-diagnostic approach to studying problems of the development of peripheral territories taking into account the specifics of economy, peculiarities of economic space organization, achieved level of socio-economic development in regions of agricultural-industrial type is a major scientific task. Its consistent solution requires not only searching for ways and tools to consolidate standard and a number of experimental diagnostic procedures, but also verifying their analytical abilities taking into account the specifics of the economic space of the center-peripheral systems of agricultural-industrial regions. The aim of the study is to inventory and characterize the possibilities and disadvantages of existing methodological approaches to the analysis and assessment of regional socio-economic differentiation in the center-periphery system. This will allow not only to identify the strengths and weaknesses of the available relevant methods, but also on this basis to move to the formulation of specific requirements for a modern analytical and diagnostic system for detecting problems of development of peripheral localities, which should take into account the need to screen and monitor a number of new diagnostic areas of analysis. The article considers a number of analytical and diagnostic areas, which are not reflected in theoretical provisions in any of the scientific directions of conceptual support of functioning and development of peripheral territories. Combining them in order to enhance the "permeability" of methods and tools of a system-diagnostic approach to peripheral research involves the development of a special methodology.

Key words: regional economy, spatial-economic systems, periphery, socio-economic differentiation, diagnostics.

Citation. Kazakov M.Y., Mitrofanova I.V. Evolution of the Scientific and Methodological Approaches to the Analysis and Assessment of Regional Socio-Economic Differentiation. Journal of Volgograd State University. Economics, 2020, vol. 22, no. 1, pp. 44-54. (in Russian). DOI: https://doi.org/10.15688/ek.jvolsu.2020.1.5
\end{abstract}

\section{ЭВОЛЮЦИЯ НАУЧНО-МЕТОДИЧЕСКИХ ПОДХОДОВ К АНАЛИЗУ И ОЦЕНКЕ РЕГИОНАЛЬНОЙ СОЦИАЛЬНО-ЭКОНОМИЧЕСКОЙ ДИФФЕРЕНЦИАЦИИ ${ }^{1}$}

\author{
Михаил Юрьевич Казаков \\ Белгородский национальный исследовательский университет, г. Белгород, Российская Федерация

\section{Инна Васильевна Митрофанова} \\ Южный научный центр РАН, г. Ростов-на-Дону, Российская Федерация
}

Аннотация. Формирование целостно-действенной методологии системно-диагностического подхода к исследованию проблем развития периферийных территорий с учетом специфики экономики, особенностей 
организации экономического пространства, достигнутого уровня социально-экономического развития в регионах аграрно-индустриального типа - крупная научная задача. Ее последовательное решение требует не только поиска способов и инструментария консолидации стандартных и ряда экспериментальных диагностических процедур, но и проверки их аналитических способностей с учетом специфики экономического пространства центро-периферийных систем регионов аграрно-индустриального типа. Целью исследования является инвентаризация и характеристика возможностей и недостатков существующих методических подходов к анализу и оценке региональной социально-экономической дифференциации в системе «центр - периферия». Это позволит не только определить сильные и слабые стороны имеющихся соответствующих методик, но и на этой основе перейти к формулированию конкретных требований к современной аналитико-диагностической системе выявления проблем развития периферийных локалитетов, которая должна учитывать необходимость скрининга и мониторинга новых диагностических областей анализа. В статье рассматривается ряд аналитических и диагностических областей, которые не отражены в теоретических положениях ни одного из научных направлений концептуального обеспечения функционирования и развития периферийных территорий. Их комбинирование в целях расширения «проницающей способности» методов и инструментария системно-диагностического подхода к исследованию периферии предполагает разработку специальной методологии.

Ключевые слова: региональная экономика, пространственно-экономические системы, периферия, социально-экономическая дифференциация, диагностика.

Цитирование. Казаков М. Ю., Митрофанова И. В. Эволюция научно-методических подходов к анализу и оценке региональной социально-экономической дифференциации // Вестник Волгоградского государственного университета. Экономика. - 2020. - Т. 22, № 1. - C. 44-54. - DOI: https://doi.org/10.15688/ek.jvolsu.2020.1.5

\section{Введение.}

\section{Научно-методическое обеспечение оценки социально-экономической дифференциаци регионов}

Любые модификации и усовершенствования методологических элементов региональных пространственных измерений необходимо начинать с инвентаризации преимуществ и недостатков имеющихся в их составе методических подходов и инструментов. Без этого нам будет сложно сформировать методологию системной диагностики периферийных территорий, что является одной из генеральных задач нашей исследовательской рефлексии.

Имеющееся методическое обеспечение для выявления глубины социально-экономической дифференциации чрезвычайно многообразно. Этот факт указывает даже не на сложность объекта исследований, а на его сверхсложность, она заключается в специфичности и многоаспектности происходящих на периферии процессов, что определяет фрагментарный характер методических подходов к диагностике.

В чем состоит эта фрагментарность? В общем виде обилие методических разработок не отражает всей остроты и номенклатуры проблем функционирования как периферийных территорий в отдельности, так и их рассмотрения во взаимоувязке с центром - с позиций системного подхода. Авторы солидар- ны с мнением С.Г. Пьянковой, отмечающей, что результататом доминирования ведомственно-отраслевого и инициированных крупными структурами корпоративного сектора экономики подходов стал несбалансированный характер развития различных сфер хозяйственного комплекса и снижение адаптивных свойств региональной и муниципальных экономических систем [Пьянкова, 2015].

На наш взгляд, несмотря на обилие методических подходов к оценке региональной социально-экономической дифференциации, в настоящий момент отсутствует цельная методология диагностического исследования территорий периферии как облигатных компонентов теоретической пространственной модели «центр периферия» во взаимоувязке с влиянием на них центра. Кроме того, требуется использование системного подхода на основе учета имманентных свойств-характеристик периферии, которые определяют ее системно-диагностические особенности как объектной категории.

Каковы сегодняшние диагностические возможности и арсенал имеющегося методического обеспечения для оценки социальноэкономической дифференциации? Для понимания этого мы провели его инвентаризацию (см. таблицу). При этом мы рассматривали сущность используемых подходов, а также учет ими системного «центро-периферийного» фактора и наглядность результатов использования. 
Оценка соответствия диагностических возможностей имеющегося методического обеспечения оценки социально-экономической дифференциации территорий современным процессам функционирования и развития периферийных территорий

\begin{tabular}{|c|c|c|c|c|c|}
\hline $\begin{array}{c}\text { Семейство методических под- } \\
\text { ходов (представители) }\end{array}$ & Сложность & $\begin{array}{c}\text { Преимущества / } \\
\text { недостатки }\end{array}$ & $\begin{array}{c}\text { Учет фактора } \\
\text { пространств ен- } \\
\text { но-экономичес- } \\
\text { кого дрейфа }\end{array}$ & $\begin{array}{c}\text { Учет витальных } \\
\text { аспектов жиз- } \\
\text { неспособности } \\
\text { и жизнестойко- } \\
\text { сти периферии }\end{array}$ & $\begin{array}{c}\text { Учет признаков } \\
\text { нарушения } \\
\text { системного } \\
\text { гомеостаза }\end{array}$ \\
\hline $\begin{array}{l}\text { Сравнительные методьл } \\
\text { (М.Н. Толмачев; О.А. Колчина, } \\
\text { М.А. Лесничая; В.Е. Реутов, } \\
\text { Д.А. Хомицкая; А.А. Тамов, } \\
\text { А.Г. Добровольский; Д. Фрум- } \\
\text { кин; В.Ю. Маслихина; } \\
\text { Ю.Д. Шмидт, В.А. Денисенко; } \\
\text { В.П. Самарина; Ю.В. Зайцева; } \\
\text { М.А. Латьшева;Н.Н. Михеева) }\end{array}$ & Средняя & $\begin{array}{l}\text { Простота и по- } \\
\text { нятность исполь- } \\
\text { зования, нагляд- } \\
\text { ность результатов } \\
\text { / сложности ис- } \\
\text { пользования } \text { ре- } \\
\text { зультатов в ком- } \\
\text { паративно-долго- } \\
\text { срочном аспекте }\end{array}$ & Не учитывают & Не учитывают & Не учитывают \\
\hline $\begin{array}{l}\text { Ранжирование и составление } \\
\text { рейтингов } \\
\text { (С.Н. Найден, А.В. Белоусова; } \\
\text { С.В. Баранов, Т.П. Скуфьина; } \\
\text { Г.А. Сульдина, А.М. Хамиду- } \\
\text { лина; Ю.Д. Шмидт, В.А. Де- } \\
\text { нисенко; Н.В. Иванова; } \\
\text { С.С. Железня ков, Е.Ю. Подо- } \\
\text { синников; С.А. Суспицин) }\end{array}$ & Умеренная & $\begin{array}{l}\text { Практически пол- } \\
\text { ное отсутствие } \\
\text { сложного матема- } \\
\text { тического аппара- } \\
\text { та, понятность ре- } \\
\text { зультатов / по- } \\
\text { верхностность } \\
\text { выводов без глу- } \\
\text { бокого анализа } \\
\text { причин }\end{array}$ & Не учитывают & Не учитывают & Не учитывают \\
\hline $\begin{array}{l}\text { Смешанные } \\
\text { (Н.В. Ворошилов, Е.С. Губа- } \\
\text { нова; А.А. Победин; } \\
\text { Е.С. Губанова, В.С. Клещ; } \\
\text { О.М. Прокапало; Г.А. Унту- } \\
\text { ра, Т.Н. Есикова, И.Д. Зай- } \\
\text { цев; И.А. Семина, А.М. Но- } \\
\text { сонов, Н.Н. Логинова; } \\
\text { С.Г. Светуньков, } \\
\text { А.В. Заграновская) }\end{array}$ & Высокая & $\begin{array}{l}\text { Позволяет полу- } \\
\text { чить всесторон- } \\
\text { нюю и разнопла- } \\
\text { новую оценку си- } \\
\text { туации / повы- } \\
\text { шенная трудоем- } \\
\text { кость и последст- } \\
\text { вия использова- } \\
\text { ния абстракций и } \\
\text { упрощений }\end{array}$ & Не учитывают & $\begin{array}{l}\text { Не учитывают } \\
\text { в большинстве } \\
\text { случаев (кро- } \\
\text { ме подходов } \\
\text { И.А. Семиной, } \\
\text { А.М. Носонова, } \\
\text { Н.Н. Логино- } \\
\text { вой) }\end{array}$ & Не учитывают \\
\hline $\begin{array}{l}\text { Пространственно-проблем- } \\
\text { ный } \\
\text { (А.Я. Троцковский, } \\
\text { И.В. Мищенко, О.А. Ми- } \\
\text { щенко) }\end{array}$ & Высокая & $\begin{array}{l}\text { Позволяет актив- } \\
\text { но задействовать } \\
\text { фактор экономи- } \\
\text { ческого простран- } \\
\text { ства в исследова- } \\
\text { нии / доминанта } \\
\text { фактора экономи- } \\
\text { ческого простран- } \\
\text { ства может иска- } \\
\text { жать итоговые } \\
\text { результаты }\end{array}$ & $\begin{array}{l}\text { Частично, в } \\
\text { части соотне- } \\
\text { сения террито- } \\
\text { рии с осью } \\
\text { «центр - пе- } \\
\text { риферия» на } \\
\text { первом этапе } \\
\text { оценки }\end{array}$ & Не учитывают & Не учитывают \\
\hline $\begin{array}{l}\text { Количественный: }{ }^{2} \text { рактор- } \\
\text { ный, кластерный и другие } \\
\text { формы многомерного анализа } \\
\text { (А.Е. Евченко; } \\
\text { С.А. Суспицин) }\end{array}$ & Средняя & 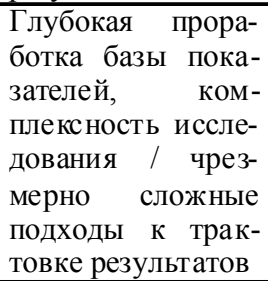 & Не учитывают & Не учитывают & Не учитывают \\
\hline $\begin{array}{l}\text { Вариационный } \\
\text { (В.В. Лазарева, Н.Ю. Власо- } \\
\text { ва, В.Н. Дъяченко; Л.С. Чер- } \\
\text { нова; Н.В. Зубаревич, } \\
\text { С.Г. Сафронов) }\end{array}$ & Средняя & $\begin{array}{l}\text { Достоверность и } \\
\text { точность эмпири- } \\
\text { ческих оценок / } \\
\text { Пониженная сте- } \\
\text { пень наглядности } \\
\text { и понятности ре- } \\
\text { зультатов }\end{array}$ & Не учитывают & Не учитывают & Не учитывают \\
\hline
\end{tabular}

Примечание. Составлено авторами. 


\section{Результаты инвентаризации имеющегося} научно-методического обеспечения оценки социально-экономической дифференциации

Имеющееся научно-методическое наследие ретроспективных исследований чрезвычайно многогранно, а использующийся инструментарий можно охарактеризовать многообразием. Так, В.Н. Толмачев на основе использования коэффициентов концентрации, индекса Тейла и его декомпозиции предлагает проводить оценку отраслевых факторов воспроизводства социально-экономической дифференциации территорий (далее - СЭДТ) при проведении межрегиональных сравнений. При этом пространственно-экономические системы центро-периферийного типа исследователем не рассматриваются [Толмачев, 2013].

О.А. Колчина и М.А. Лесничая предложили использование свертки тематических интегральных показателей в комплексный и последующее исчисление коэффициентов неравномерности и вариации для проведения внутрирегиональных сопоставлений без разделения объекта анализа на центр и периферию [Колчина и др., 2018].

С.Н. Найден и А.В. Белоусова используют ранжирование и присвоение рейтинговых оценок регионам по комплексу показателей [Найден и др., 2017].

В исследовании Н.В. Ворошилова и Е.С. Губановой проводится оценка глубины дифференциации с использованием показателей вариации, выполняется типологизация территорий на основе интегрального показателя уровня социально-экономического развития, выявляются факторы СЭДТ (на базе проверки $\beta$-конвергенции) [Ворошилов и др., 2018]. При этом рассматривается региональная периферия без учета центра.

В.Е. Реутов и Д.А. Хомицкая на основе отбора показателей по 6 направлениям диагностики в сочетании с 12 методами исчисления вариации предлагают сформировать целостную картину территориальных диспропорций при рассмотрении региональных социоэкологоэкономических систем [Реутов и др., 2017].

С.В. Барановым и Т.П. Скуфьиным используется методика совета по изучению производительных сил (9 компонентов, одинако- вый вес каждого индикатора): по каждому индикатору строится ранг региона, начиная с лучшего, дается интегральная бальная оценка показателей. Авторы также используют статистику $T^{2}$-Хоттелинга. Регионы разбиваются по группам для составления итогового рейтинга [Баранов и др., 2008]. Кроме того, дополнить методику Министерства развития и торговли РФ рядом социально значимых индикаторов предлагает Д. Фрумкин. На основе расчета индексов по каждому показателю и их сравнения со среднероссийским уровнем им производится группировка регионов [Фрумкин, 2008].

А.А. Тамов и А.Г. Добровольский предлагают проводить межрегиональные сравнения и оценивать дифференциацию по одному или нескольким показателям [Тамов, 2013].

А.Я. Троцковский, И.В. Мищенко и О.А. Мищенко рассматривают регион как центро-периферийную систему: ими сформулирован принцип детерминизма социальноэкономической дифференциации территорий их принадлежности к уровням системы «центр - периферия». Для оценки глубины СЭДТ авторами предлагается трехшаговая методика: 1 шаг - территории распределяются по оси «центр - периферия»; 2 шаг построение частных классификаций в соответствии с остротой проблем экономики, демографии и социальной сферы; 3 шаг - проекция частных классификаций на типологию территорий в системе «центр - периферия» [Троцковский и др., 2014].

Социально-экономическая асимметрия как пространственный фактор неоднородности развития внутрирегиональных территорий рассматривается А.Е. Евченко в качестве индикативного признака. Используя корреляционный анализ, исследователь проводит группировку районов в кластеры по уровню социально-экономического развития [Евченко, 2005].

В.Ю. Мыслихина предлагает разложение СЭДТ на социальную и экономическую компоненты. Дифференциация оценивается на основе использования индекса Тейла и Аткинсона, которые, как она обосновывает, наиболее информативны [Маслихина, 2013].

Авторскую методику оценки глубины СЭДТ предлагает А.А. Победин. В ней уче- 
ный объединяет методы вариационного, многомерного, проблемного и комплексного анализа СЭДТ. С использованием подобного методического конгломерата автор формирует 7 кластеров районов Свердловской области [Победин, 2011].

Использовать методику составления многоуровневых интегральных показателей в разрезе 6 параметров измерения СЭДТ с проверкой корреляционной связи отобранных индикаторов для проведения внутрирегиональных сопоставлений муниципальных образований предлагают Г.А. Сульдина и А.М. Хамидулина [Сульдина и др., 2012].

Авторская методика Ю.Д. Шмидт и В.А. Денисенко базируется на использовании 35 сопоставимых показателей с последующим расчетом интегральных показателей и многомерной группировкой муниципальных образований (районов) [Шмидт и др., 2008].

Стоит отметить работу коллектива авторов В.В. Лазаревой, Н.Ю. Власовой, В.Н. Дъяченко. Ими исследуются приграничные муниципальные районы, выделяются центры районов различного типа и учитываются уровни периферии. Кроме того, принимается во внимание региональный центр. Авторы используют при оценке СЭДТ среднее значение, стандартное отклонение, коэффициент вариации, асимметрии и эксцесса [Лазарева и др., 2019]. Коэффициенты вариации региональных показателей использует также Л.С. Чернова [Чернова, 2007]. Расчеты с синхронным использованием коэффициента вариации и коэффициента Джини при межрегиональных и межгородских сопоставлениях отражены в исследовании Н.В. Зубаревич и С.Г. Сафронова [Зубаревич и др., 2013].

Специфический инструментарий оценки глубины СЭДТ предлагает В.П. Самарина. Ею осуществлена комплексная оценка неравномерности социально-экономического развития с использованием коэффициента неоднородности, базирующегося на свойствах сходства Имбри-Парди [Самарина, 2008].

Масштабное исследование по межрегиональным сопоставлениям в уровне социально-экономического развития в разрезе 79 регионов РФ провели Ю.В. Зайцева и М.А. Латышева. Ими применялись коэффициенты вариации, дисперсии, куртозиса, Джини, а также индексы Герфиндаля и Тейла [Зайцева и др., 2010].

Совмещение 5 различных частных и интегрального рейтингов при типологизации регионов по комплексу индикаторов социально-экономического развития предлагает Н.В. Иванова [Иванова, 2013].

Н.Н. Михеева территориальные различия предлагает оценивать в разрезе индикаторов сдвигов в пространственной структуре производства и его факторов, используя специальный коэффициент различия структур [Михеева, 2008].

В работе О.М. Прокапало пространственная дифференциация оценивается комплексом методов: сравнения удельных показателей, расчет коэффициента вариации, сравнение темпов роста, сравнение структуры размещения инвестиций и т. д. Также исследователем используются типологические группировки [Прокапало, 2010].

Известный исследователь территориальной социально-экономической дифференциации С.А. Суспицин при разработке комплекса методик обустройства корректных межрегиональных сопоставлений использует различные приемы рейтинговых оценок, инвариантной кластеризации [Суспицин, 2017].

Группа исследователей - Г.А. Унтура, Т.Н. Есикова и И.Д. Зайцев - предлагает комплексно использовать ранжирование и нормирование показателей, многомерный сравнительный анализ, индексы межрегиональных сопоставлений, в том числе композитные, рейтинги и типологические группировки [Унтура и др., 2016].

Формализованные методы оценки инструментами социометрии рекомендовали применять и апробировали И.А. Семина, А.М. Носонов, Н.Н. Логинова [Семина и др., 2016].

Отметим также исследования, в которых предлагаются использовать при оценке СЭДТ индексный метод, метод динамического норматива, а также комплекснозначные показатели [Светуньков и др., 2012].

Безусловно, охватить абсолютно все исследования и привести содержащиеся в них методические положения по оценке СЭДТ не представляется возможным - такая задача в данной работе не стоит. Вместе с тем рассмотрение имеющегося массива позволяет 
сформулировать обобщающий вывод: преимущественно современные использующиеся методы оценки СЭДТ не учитывают статус территорий в системе «центр - периферия», что «выключает» фактор пространственной локализации из детерминант социально-экономической дифференциации. Кроме того, применяющиеся методики в большей степени направлены на исследование межрегиональной дифференциации, а внутрирегиональная (между муниципалитетами) преимущественно остается за гранью эмпирических исследований.

\section{Диагностические возможности оценки социально-экономической дифференциации территорий}

На втором этапе мы провели комплексную оценку соответствия диагностических возможностей имеющегося методического обеспечения оценки СЭДТ современным процессам функционирования и развития периферийных территорий. Результаты отражены в таблице. Как видно из ее материалов, в совокупности методов оценки социально-экономической дифференциации территорий наиболее востребованными являются разнообразные варианты сравнительных методов и группы методов, предполагающих ранжирование и составление рейтингов территорий. Также распространены подходы, основанные на комбинировании различных методов для получения разнокачественных оценок по комплексу характеристик и их последующее совмещение. Данный методический прием - проекционное наложение оценок, матриц, рейтингов, типологий и т. д. - особенно востребован при проверке гипотез причинной обусловленности возникновения и углубления / нивелирования социально-экономической дифференциации. В этом плане интересны подходы, инкорпорирующие фактор экономического пространства в оценочный блок [Троцковский и др., 2014]. Кроме того, в отличие от большинства предложенных и реализованных подходов только в одном исследовании была осуществлена попытка разграничить территориальную социально-экономическую дифференциацию по степени ее глубины: дифференциация-асимметрия-поляризация [Губанова и др., 2018].
Наиболее популярные и в то же время наименее трудозатратные методы оценки СЭДТ дают своего рода «плоскую» картину изучаемого явления и процесса. В этом плане смешанные и пространственно обусловленные методы оценки дают более «объемную» картину того, что для целей формирования методологических основ системной диагностики территориального развития является более предпочтительным.

\section{Методологические проблемы формирования системной диагностики социально-экономической дифференциации территорий}

Переходя к методологическим аспектам диагностики проблем развития периферийных территорий с учетом анализа диагностических возможностей имеющегося методического обеспечения оценки СЭДТ, обозначим ряд имеющихся проблем, требующих своего решения в дальнейшем. Восполнение выявленных нами методологических «пустот» применительно к формированию методологии системной диагностики СЭДТ как одному из аспектов функционирования и развития периферии - серьезная научная проблема, решение которой открывает возможности для разработки универсальных принципов и механизмов устранения подобного рода неравномерности, доведения ее до некритических параметров.

Во-первых, имеющееся методическое обеспечение оценки СЭДТ в составе комплексной методологии системно-диагностического подхода к исследованию проблем развития периферийных территорий не учитывает фактор экономического пространства, а именно «центро-периферийную систему координат». В чем это выражается? В том, что изначально уровень социально-экономического развития территории не соотносится с ее институциональным статусом, пространственной локализацией и рассматривается с позиций факторов первой и второй природы. Кроме того, территория, при всей очевидности неизменности ее географического расположения, отнюдь не статична в пространственно-экономическом плане. В этом плане оценку СЭДТ необходимо вести с учетом пространственно-экономической динамики территории, типа ее 
динамической включенности в экономическое пространство: именно с этим фактором связывать изменение уровня социально-экономического развития, который в рамках модели «центр - периферия» зависит от экономической близости к центру.

Во-вторых, имеющееся методическое обеспечение оценки СЭДТ не учитывает и не отражает витальные аспекты жизнеспособности и жизнестойкости периферии. Иными словами, за индикаторами, показателями и параметрами не видно конкретной жизни населения как главного актора периферии, не понятно, чувствует ли население положительные изменения, связанные с повышением уровня социально-экономического развития.

В-третьих, существующие методы оценки СЭДТ исходят из их «системного постоянства» и не принимают в расчет возможное нарушение гомеостаза периферии как обязательного диалектического элемента рассматриваемых центро-периферийных системных формирований. Это постоянство выражается не только в морфофункциональной структуре территории как таковой, но и определяется через конкретные признаки (симптомы) нарушения пространственного гомеостаза.

\section{Заключение}

Проведенный в настоящей статье анализ имеющегося методического обеспечения оценки СЭДТ, выявленные его недостатки с позиций научно обоснованного формирования методологии системно-диагностического исследования периферийных территорий позволяют далее перейти нам к формулированию специфических требований к аналитико-диагностической системе исследования периферии как своего рода рамочных целевых свойств, которыми должна обладать данная система:

1. Требование всестороннего охвата аспектов функционирования объекта диагностики: экономико-географического, пространственно-экономического, социально-экономического, институционально-инфраструктурного и т. д., что позволит сформировать максимально полную и комплексную картину происходящих процессов.

2. Сочетание объективных оценок как отражения формально-параметральной сторо- ны процессов функционирования и развития территории и субъективных суждений ее агентов для соблюдения требования единства количественной и качественной оценки.

3. Требование возможности совмещения результатов различных процедур диагностики для проверки ряда гипотез, имеющих комплексную природу и характеризующих процессы функционирования и развития периферийных территорий как сложных системных компонентов.

4. Система диагностики проблем развития периферийных территорий, позволяющая провести оценку и анализ социально-экономической дифференциации территорий, должна учитывать комплекс специфических особенностей функционирования экономической сферы, обусловленных специализацией и местом региона в национальной системе разделения труда.

5. Система диагностики проблем развития периферийных территорий должна предусматривать возможности идентификации территориально-уровневого распределения объектов диагностики (периферийных территорий различного типа) в системе «центр периферия». Это позволит включить фактор экономического пространства в процедурные блоки диагностики и «связать» получаемые результаты с расположением конкретных объектов диагностики на оси «центр - периферия».

6. Требование наличия возможности комбинационного синхронного использования различных методов диагностики для установления глубины социально-экономической дифференциации, расширенного выявления спектра причинной обусловленности территориальной неравномерности развития локалитетов, проверки ряда гипотез инерционно-наследственной и эволюционно-приобретенной природы.

7. Система диагностики должна предусматривать применение организационно-методических возможностей диагностики типа пространственно-экономического дрейфа периферии и идентификации характера ее взаимодействия с центром.

8. Одним из ключевых методологически значимых требований можно считать предусмотрение возможности исследования факторов и условий жизнеспособности и жизне- 
стойкости территорий в контексте оценки вероятности функционирования территории в дальнейшем или возможности ее исчезновения, что для периферии является особенно актуальным. Комплементарным требованием также будет являться необходимость диагностики симптомокомплекса нарушения территориального гомеостаза.

Данные требования целесообразно в приоритетном порядке учитывать при формировании системы диагностики периферийных территорий как компонентов центро-периферийных структурных образований.

\section{ПРИМЕЧАНИЕ}

${ }^{1}$ Публикация подготовлена в рамках реализации Государственного задания Южного научного центра РАН на 2020 г., № государственной регистрации проекта АААА-A19-119011190184-2.

The reported publication was carried out in the framework of implementing the State Task of the Southern Scientific Centre of the Russian Academy of Sciences for 2020, project state registration no. AAAA-A19-119011190184-2.

\section{СПИСОК ЛИТЕРАТУРЫ}

Баранов, С. В. Новые методики и результаты исследования межрегиональной дифференциации на основе метода главных компонент / С. В. Баранов, Т. П. Скуфьина // Вестник Мурм. гос. техн. ун-та. - 2008. - Т. 11, № 2. - С. 201-210.

Ворошилов, Н. В. Дифференциация территорий и механизм ее снижения / Н. В. Ворошилов, Е. С. Губанова // Экономические и социальные перемены: факты, тенденции, прогно3. - 2018. - Т. 11, № 6. - С. 57-72.

Губанова, Е. С. Методика оценки неравномерности социально-экономического развития региона / Е. С. Губанова, В. С. Клещ // Проблемы развития территории. - 2018. - № 6. C. $30-41$.

Евченко, А. Е. Применение экономико-математических методов для анализа территориальной социально-экономической асимметрии и выбора целевых ориентиров развития районов / А. Е. Евченко // Вестник Воронеж. гос. ун-та. Сер.: Экономика и управление. - 2005. № 2. - C. 191-197.

Зайцева, Ю. В. Исследование дифференциации российских регионов по уровню социально-экономического развития с помощью простей- ших индикаторов / Ю. В. Зайцева, М. А. Латышева // Современная экономика: проблемы и решения. - 2010. - № 2. - С. 6-15.

Зубаревич, Н. В. Неравенство социально-экономического развития регионов и городов России 2000-х годов: рост или снижение? / Н. В. Зубаревич // Общественные науки и современность. - 2013. - № 6. - С. 15-26.

Иванова, Н.В. Методика оценки пространственной дифференциации экономики регионов России / Н. В. Иванова // Экономика. Право. Налоги. - 2013. - № 6. - С. 63-70.

Колчина, О. А. Модель оценки межмуниципальной социально-экономической дифференциации / О. А. Колчина, М. А. Лесничая // Экономика: вчера, сегодня, завтра. - 2018. - Т. 8, № 11А. C. 64-75.

Лазарева, В. В. Неравномерность развития муниципальных образований Дальневосточного приграничья / В.В.Лазарева, Н. Ю. Власова, В. Н. Дьяченко // Известия Урал. гос. экон. унта. - 2019. - Т. 20, № 1. - С. 61-77.

Маслихина, В. Ю. Количественная оценка экономического и социального пространственного неравенства в Приволжском федеральном округе / В. Ю. Маслихина // Науковедение. 2013. - № 4. - С. 4-10.

Михеева, Н. Н. Региональные пропорции экономического роста в России / Н. Н. Михеева // Регион: экономика и социология. - 2008. - № 2. C. 225-243.

Найден, С. Н. Пространственная неоднородность благосостояния населения: Хабаровский край в межрегиональных сопоставлениях / С. Н. Найден, А. В. Белоусова // Карел. науч. журн. 2017. - Т. 6, №4 (21). - С. 255-259.

Победин, А. А. Методика анализа социально-экономического развития муниципальных образований / А. А. Победин // Муниципальная экономика и управление. - 2011. - № 1 .

Прокапало, О. М. Пространственная дифференциация макроэкономических индикаторов в российской экономике / О. М. Прокапало // Пространственная экономика. - 2010. - № 1. C. 36-54.

Пьянкова, С. Г. Теория и методология системного социально-экономического развития монопрофильных территорий на основе институционального обновления : дис. ... д-ра экон. наук : 08.00.05 / Пьянкова Светлана Григорьевна. - Екатеринбург, 2015. - 479 с.

Реутов, В. Е. Методика выявления социально-экономических диспропорций регионального развития / В. Е. Реутов, Д. А. Хомицкая // Экономика: вчера, сегодня, завтра. - 2017. - Т. 7, № 2A. - C. $145-158$. 
Самарина, В. П. Оценка неравномерности социально-экономического развития субъектов центрально-черноземного экономического района / В. П. Самарина // Региональная экономика: теория и практика. - 2008. - № 8 (65). C. 33-38.

Светуньков, С. Г. Комплекснозначный анализ и моделирование неравномерности социальноэкономического развития регионов России / С. Г. Светуньков, А. В. Заграновская, И. С. Светуньков. -СПб. : [б. и.], 2012. - 129 с.

Семина, И. А. Пространственный анализ и оценка социально-экономического развития региона : монография / И. А. Семина, А. М. Носонов, Н. Н. Логинова. - Саранск : Изд-во Морд. унта, 2016. $-228 \mathrm{c}$.

Сульдина, Г. А. Оценка сбалансированности социально-экономического развития муниципальных образований в регионе / Г. А. Сульдина, А. М. Хамидулина // Экономические науки. 2012. - № 2 (87). - С. 244-248.

Суспицин, С. А. Методы и модели координации долгосрочных решений в системе «национальная экономика - регионы» / С. А. Суспицин. - Новосибирск : ИЭОПП СО РАН, 2017.$296 \mathrm{c}$.

Тамов, А. А. Теоретико-методологические аспекты исследования межрегиональной социально-экономической дифференциации в пространстве макрорегиона / А. А. Тамов, А. Г. Добровольский // Вестник Адыг. гос. ун-та. Сер. 5: Экономика. -2013 . - № 1. - С. 75-79.

Толмачев, М. Н. Методы исследования социальноэкономической дифференциации российских регионов / М. Н. Толмачев // Экономика и социум. - 2013. - № 4. - С. 789-798.

Троцковский, А. Я. Пространственное развитие сельской периферии: методология и основные результаты исследования / А. Я. Троцковский, И. В. Мищенко, О. А. Мищенко // Региональная экономика: теория и практика. 2014. - № 45. - С. 2-16.

Унтура, Г. А. Методы социально-экономической диагностики иерерхических территориальных систем (на базе ПК «ПАВИСЭР») / Г. А. УНтура, Т. Н. Есикова, Д. А. Зайцев. - Новосибирск : ИЭОПП СО РАН, 2016. - 192 с.

Фрумкин, Д. Методологические подходы к изучению социально-экономической дифференциации регионов / Д. Фрумкин // Вестник Ин-та экон. РАН. - 2008. - № 3. - С. 206-211.

Чернова, Л. С. Тенденции региональной дифференциации уровней социального развития субъектов Российской Федерации / Л. С. Чернова // Проблемы прогнозирования. - 2007. № 6. - С. 58-65.
Шмидт, Ю. Д. Дифференциация и регулирование социально-экономического развития муниципальных образований региона / Ю. Д. Шмидт, В. А. Денисенко // Вестник Тихоокеан. гос. экон. ун-та. -2008. - № 3 (47). - С. 3-14.

\section{REFERENCES}

Baranov S.V., Skufyina T.P. Novye metodiki i rezultaty issledovaniya mezhregionalnoy differentsiatsii na osnove metoda glavnykh komponent [New Methods and Results of the Study of Interregional Differentiation Based on the Method of Principal Components]. Vestnik Murmanskogo gosudarstvennogo tekhnicheskogo universiteta [Vestnik of MSTU], 2008, vol. 11, no. 2, pp. 201-210.

Voroshilov N.V., Gubanova E.S. Differentsiatsiya territoriy i mekhanizm ee snizheniya [Differentiation of Territories and the Mechanism of Its Reduction]. Ekonomicheskie $i$ sotsialnye peremeny: fakty, tendentsi, prognoz [Economic and Social Changes: Facts, Trends, Forecast], 2018, vol. 11, no. 6, pp. 57-72.

Gubanova E.S., Kleshch V.S. Metodika otsenki neravnomernosti sotsialno-ekonomicheskogo razvitiya regiona [Methodology for Assessing the Uneven Socio-Economic Development of the Region]. Problemy razvitiya territorii [Problems of Territory's Development], 2018, no. 6, pp. 30-41.

EvchenkoA.E. Primenenie ekonomiko-matematicheskikh metodov dlya analiza territorialnoy sotsialnoekonomicheskoy asimmetrii i vybora tselevykh orientirov razvitiya rayonov [Application of Economic and Mathematical Methods for the Analysis of Territorial Socio-Economic Asymmetry and the Choice of Targets for the Development of Districts]. Vestnik Voronezhskogo gosudarstvennogo universiteta Seriya: Ekonomika i upravlenie [Proceedings of Voronezh State University. Series: Economy and Management Communication], 2005, no. 2, pp. 191-197.

Zaitseva Yu.V., Latysheva M.A. Issledovanie differentsiatsii rossiyskikh regionov po urovnyu sotsialno-ekonomicheskogo razvitiya $\mathrm{s}$ pomoshchyu prosteyshikh indikatorov [Study of Differentiation of Russian Regions by the Level of Socio-Economic Development Using the Simplest Indicators]. Sovremennaya ekonomika: problemy i resheniya [Modern Economy: Problems and Solutions], 2010, no. 2, pp. 6-15.

Zubarevich N.V. Neravenstvo sotsialnoekonomicheskogo razvitiya regionov i gorodov 
Rossii 2000-kh godov: rost ili snizhenie? [Inequality of Socio-Economic Development of Regions and Cities of Russia in the 2000s: Growth or Decline?]. Obshchestvennye nauki i sovremennost [Social Sciences and Contemporary World], 2013, no. 6, pp. 15-26.

Ivanova N.V. Metodika otsenki prostranstvennoy differentsiatsii ekonomiki regionov Rossii [Methodology of Estimation of Spatial Differentiation of Economy of Regions of Russia]. Ekonomika. Pravo. Nalogi, 2013, no. 6, pp. 63-70.

Kolchina O.A., Lesnichaya M.A. Model otsenki mezhmunitsipalnoy sotsialno-ekonomicheskoy differentsiatsii [Model of Evaluation of Intermunicipal Socio-Economic Differentiation]. Ekonomika: vchera, segodnya, zavtra [Economics: Yesterday, Today and Tomorrow], 2018, vol. 8, no. 11A, pp. 64-75.

Lazareva V.V., Vlasova N.Yu., Dyachenko V.N. Neravnomernost razvitiya munitsipalnykh obrazovaniy Dalnevostochnogo prigranichya [Uneven Development of Municipalities of the Far Eastern Frontier]. Izvestiya Uralskogo gosudarstvennogo ekonomicheskogo universiteta [Journal of the Ural State University of Economics], 2019, vol. 20, no. 1, pp. 61-77.

Maslikhina V.Yu. Kolichestvennaya otsenka ekonomicheskogo i sotsialnogo prostranstvennogo neravenstva v Privolzhskom federalnom okruge [Quantitative Assessment of the Economic and Social Spatial Inequality in the Volga Federal District]. Internet-zhurnal «Naukovedenie» [The Eurasian Scientific Journal], 2013, no. 4, pp. 4-10.

Mikheeva N.N. Regionalnye proportsii ekonomicheskogo rosta $\mathrm{v}$ Rossii [Regional Proportions of Economic Growth in Russia]. Region: ekonomika i sotsiologiya [Regional Research of Russia], 2008, no. 2, pp. 225-243.

Naiden S.N., Belousova A.V. Prostranstvennaya neodnorodnost blagosostoyaniya naseleniya: Khabarovskiy kray v mezhregionalnykh sopostavleniyakh [Spatial Heterogeneity of Population Welfare: Khabarovsk Krai in Interregional Comparisons]. Karelskiy nauchnyy zhurnal [Karelian Scientific Journal], 2017, vol. 6, no. 4 (21), pp. 255-259.

Pobedin A.A. Metodika analiza sotsialnoekonomicheskogo razvitiya munitsipalnykh obrazovaniy [Methods of Analysis of SocioEconomic Development of Municipalities]. Munitsipalnaya ekonomika i upravlenie, 2011, no. 1.

Prokapalo O.M. Prostranstvennaya differentsiatsiya makroekonomicheskikh indikatorov $\mathrm{v}$ rossiyskoy ekonomike [Spatial Differentiation of
Macroeconomic Indicators in the Russian Economy]. Prostranstvennaya ekonomika [Spatial Economics], 2010, no. 1, pp. 36-54.

Pyankova S.G. Teoriya i metodologiya sistemnogo sotsialno-ekonomicheskogo razvitiya monoprofilnykh territoriy na osnove institutsionalnogo obnovleniya: dis.... d.e.n. [Theory and Methodology of System SocioEconomic Development of Single-Industry Territories on the Basis of Institutional Renewal. Dr. econ. sci. diss.]. Yekaterinburg, $2015.479 \mathrm{p}$.

Reutov V.E., Khomitskaya D.A. Metodika vyyavleniya sotsialno-ekonomicheskikh disproportsiy regionalnogo razvitiya [Methods of Identifying Socio-Economic Imbalances of Regional Development]. Ekonomika: vchera, segodnya, zavtra [Economics: Yesterday, Today, Tomorrow], 2017, vol. 7, no. 2A, pp. 145-158.

Samarina V.P. Otsenka neravnomernosti sotsialnoekonomicheskogo razvitiya subyektov tsentralno-chernozemnogo ekonomicheskogo rayona [Assessment of the Uneven SocioEconomic Development of the Subjects of the Central Chernozem Economic District]. Regionalnaya ekonomika: teoriya i praktika [Regional Economy: Theory and Practice], 2008, no. 8 (65), pp. 33-38.

Svetunkov S.G., Zagranovskaya A.V., Svetunkov I.S. Kompleksnoznachnyy analiz i modelirovanie neravnomernosti sotsialno-ekonomicheskogo razvitiya regionov Rossii [Complex-Valued Analysis and Modeling of Uneven SocioEconomic Development of Russian Regions]. Saint Petersburg, 2012. $129 \mathrm{p}$.

Semina I.A., Nosonov A.M., Loginova N.N. Prostranstvennyy analiz $i$ otsenka sotsialnoekonomicheskogo razvitiya regiona: monografiya [Spatial Analysis and Assessment of Socio-Economic Development of the Region. Monograph.], Saransk, Izd-vo Mordovskogo universiteta, 2016. $228 \mathrm{p}$.

Suldina G.A., Khamidulina A.M. Otsenka sbalansirovannosti sotsialno-ekonomicheskogo razvitiya munitsipalnykh obrazovaniy v regione [Assessment of the Balance of Socio-Economic Development of Municipalities in the Region]. Ekonomicheskie nauki [Economic Sciences], 2012, no. 2 (87), pp. 244-248.

Suspitsin S.A. Metody i modeli koordinatsii dolgosrochnykh resheniy $v$ sisteme "natsionalnaya ekonomika - regiony» [Methods and Models of Coordination of LongTerm Decisions in the System "National Economy - Regions"]. Novosibirsk, IEOPP SO RAN, 2017. $296 \mathrm{p}$. 
Tamov A.A., Dobrovolsky A.G. Teoretikometodologicheskie aspekty issledovaniya mezhregionalnoy sotsialno-ekonomicheskoy differentsiatsii v prostranstve makroregiona [Theoretical and Methodological Aspects of the Study of Interregional Socio-Economic Differentiation in the Space of the Macroregion]. Vestnik Adygeyskogo Gosudarstvennogo Universiteta. Seriya 5: ekonomika [Bulletin of Adygea State University. Series 5: Economics], 2013, no. 1, pp. 75-79.

Tolmachev M.N. Metody issledovaniya sotsialnoekonomicheskoy differentsiatsii rossiyskikh regionov [Methods of Research of SocioEconomic Differentiation of Russian Regions]. Ekonomika i sotsium, 2013, no. 4, pp. 789-798.

Trotskovskii A.Ya., Mishchenko I.V., Mishchenko O.A. Prostranstvennoe razvitie selskoy periferii: metodologiya i osnovnye rezultaty issledovaniya [Spatial Development of Rural Periphery: Methodology and Main Results of Research]. Regionalnaya ekonomika: teoriya i praktika [Regional Economy: Theory and Practice], 2014, no. 45, pp. 2-16.

Untura G.A., Esikova T.N., Zaytsev D.A. Metody sotsialno-ekonomicheskoy diagnostiki iererkhicheskikh territorialnykh sistem (na baze $P K$ «PAVISER») [Methods of SocioEconomic Diagnostics of Hierarchical Territorial Systems (Based on PC "PAVISER")]. Novosibirsk, IEOPP SO RAN, 2016. 192 p.

Frumkin D. Metodologicheskie podkhodyk izucheniyu sotsialno-ekonomicheskoy differentsiatsii regionov [Methodological Approaches to the Study of Socio-Economic Differentiation of Regions]. Vestnik Instituta ekonomiki Rossiyskoy Akademii Nauk [The Bulletin of the Institute of Economics of the Russian Academy of Sciences], 2008, no. 3, pp. 206-211.

Chernova L.S. Tendentsii regionalnoy differentsiatsii urovney sotsialnogo razvitiya subyektov Rossiyskoy Federatsii [Tendencies of Regional Differentiation of Levels of Social Development of Subjects of the Russian Federation]. Problemy prognozirovaniya [Studies on Russian Economic Development], 2007, no. 6, pp. 58-65.

Schmidt Yu.D., Denisenko V.A. Differentsiatsiya i regulirovanie sotsialno-ekonomicheskogo razvitiya munitsipalnykh obrazovaniy regiona [Differentiation and Regulation of Socio-Economic Development of Municipalities in the Region]. Vestnik Tikhookeanskogo gosudarstvennogo ekonomicheskogo universiteta [Bulletin of PNU], 2008, no. 3 (47), pp. 3-14.

\section{Information About the Authors}

Mikhail Y. Kazakov, Candidate of Sciences (Economics), Doctoral Student, Institute of Economics and Management, Belgorod National Research University, Pobedy St., 85, 308015 Belgorod, Russian Federation, lyasay21@yandex.ru, https://orcid.org/0000-0002-0297-6299

Inna V. Mitrofanova, Doctor of Sciences (Economics), Professor, Leading Researcher, Laboratory of Regional Economics, Federal Research Centre The Southern Scientific Centre of the Russian Academy of Sciences, Chekhov St., 41, 344006 Rostov-on-Don, Russian Federation, mitrofanova@volsu.ru,https://orcid.org/0000-0003-1685-250X

\section{Информация об авторах}

Михаил Юрьевич Казаков, кандидат экономических наук, докторант Института экономики и менеджмента, Белгородский национальный исследовательский университет, ул. Победы, 85, 308015 г. Белгород, Российская Федерация, lyasay21@yandex.ru, https://orcid.org/0000-0002-0297-6299

Инна Васильевна Митрофанова, доктор экономических наук, профессор, главный научный сотрудник лаборатории региональной экономики, Южный научный центр РАН, просп. Чехова, 41, 344006 г. Ростов-на-Дону, Российская Федерация, mitrofanova@volsu.ru, https://orcid.org/0000-0003-1685-250X 